\title{
A comparative study of pregnancy outcomes among women with and without threatened miscarriage in the first trimester in Abakaliki Southeast Nigeria
}

\section{Johnbosco Ifunanya Nwafor*, Victor Jude Uchenna Onuchukwu, Vitus Okwuchukwu Obi, Darlinghton-Peter Chibuzor Ugoji, Blessing Idzuinya Onwe, Chukwunenye Chukwu Ibo, Chuka Nobert Obi}

Department of Obstetrics and Gynaecology, Alex Ekwueme Federal University Teaching Hospital, Abakaliki, Ebonyi State, South-East Nigeria

Received: 16 June 2019

Accepted: 30 July 2019

*Correspondence:

Dr. Johnbosco Ifunanya Nwafor,

E-mail: nwaforjohnbosco97@gmail.com

Copyright: (C) the author(s), publisher and licensee Medip Academy. This is an open-access article distributed under the terms of the Creative Commons Attribution Non-Commercial License, which permits unrestricted non-commercial use, distribution, and reproduction in any medium, provided the original work is properly cited.

\footnotetext{
ABSTRACT

Background: Threatened miscarriage is the commonest complication of pregnancy and has been associated with adverse pregnancy outcomes. Therefore, the aim of this study is to determine the association between threatened miscarriage and adverse maternal and perinatal outcomes.

Methods: This was a retrospective case-control study undertaken at the Alex Ekwueme Federal University Teaching Hospital, Abakaliki. The study involved 228 women presenting with threatened miscarriage in the first trimester and 228 asymptomatic matched controls. The statistical analysis was done using Epi info version 7.1.5, March 2015 (CDC, Atlanta, Georgia, USA).

Results: Women with threatened miscarriage were more likely to have preterm delivery $(\mathrm{OR}=7.1,95 \% \mathrm{CI}=3.51$ 14.32, $\mathrm{P}<0.0001)$, placenta praevia $(\mathrm{OR}=2.4,95 \% \mathrm{CI}=1.13-5.26, \mathrm{P}=0.03)$, placental abruption $(\mathrm{OR}=3.6,95 \%$ $\mathrm{CI}=1.40-9.03, \mathrm{P}=0.01)$ and retained placenta $(\mathrm{OR}=2.9,95 \% \mathrm{CI}=1.18-6.97, \mathrm{P}=0.02)$. Similarly, women with first trimester threatened miscarriage were more likely to develop postpartum haemorrhage $(\mathrm{OR}=2.4,95 \%$ $\mathrm{CI}=1.17-5.06, \mathrm{P}=0.02$ ). There was no significant differences in the stillbirth rate, Apgar scores at 5 minutes less than 7, admission into neonatal intensive care unit and early neonatal death. Threatened miscarriage was associated with intrauterine growth restriction $(\mathrm{OR}=3.5,95 \% \mathrm{CI}=1.77-6.88, \mathrm{P}<0.0001)$ and low birth weight $<2 . \mathrm{kg}$ $(\mathrm{OR}=3.2,95 \% \mathrm{CI}=1.33-7.69, \mathrm{P}=0.01)$.

Conclusions: Women with threatened miscarriage in the first trimester are at increased risk of adverse pregnancy outcomes and the risk factors should be taken into consideration when deciding upon antenatal surveillance and management of their pregnancies.
}

Keywords: Abakaliki, Adverse, Miscarriage, Maternal, Perinatal, Threatened

\section{INTRODUCTION}

Bleeding during pregnancy can cause maternal anxiety and emerging evidence suggests that it may be associated with poor fetal and maternal outcomes. ${ }^{1}$ Threatened miscarriage is diagnosed on the basis of documented fetal cardiac activity on ultrasound with a history of vaginal bleeding in the presence of a closed cervix. ${ }^{1-4}$ First- 
trimester bleeding is a common complication which affects $16-25 \%$ of all pregnancies. ${ }^{4-6}$ About half of these will end in miscarriage within 20 weeks of gestation and those women who remain pregnant have an increased risk of developing other complications later in pregnancy. ${ }^{7}$

It is hypothesized that first-trimester bleeding may indicate an underlying placental dysfunction, which may manifest later in pregnancy causing adverse outcomes such as increased risk of pre-eclampsia, preterm delivery, preterm prelabour rupture of membranes (PPROM), placental abruption and intrauterine growth restriction (IUGR). ${ }^{1-9}$ Currently threatened miscarriage is not considered as a risk factor in relation to adverse maternal and perinatal outcomes in pregnancy apart for the specific period of active bleeding even though several studies conducted in the past have shown an association between early pregnancy bleeding and adverse pregnancy outcomes. ${ }^{8}$ Knowledge about the outcome of ongoing pregnancies following first-trimester bleeding is relevant to both women and their obstetricians in order to plan antenatal care and consider clinical interventions in pregnancy. This will help in reducing poor maternal and perinatal outcomes. ${ }^{9-11}$

No studies have been reported on the association of early pregnancy bleeding and adverse pregnancy outcomes in Abakaliki. Therefore, the aim of the study is to determine association between threatened miscarriage and adverse maternal and perinatal outcomes in the hospital.

\section{METHODS}

This was a 7-year retrospective case-control study undertaken between $1^{\text {st }}$ January 2012 and $31^{\text {st }}$ December 2018 at the Alex Ekwueme Federal University Teaching Hospital, Abakaliki.

Threatened miscarriage in the study was defined as the presence of vaginal bleeding within the first trimester of pregnancy, closed cervical on speculum examination and ultrasound confirmation of fetal viability. The cohorts were women who had threatened miscarriage in the first trimester and carried the pregnancy beyond the age of viability (>28weeks). Controls were all women that delivered after 28 weeks within the study period, but without history of first-trimester bleeding. The cases and controls were matched for age, marital status, parity and body mass index.

The exclusion criteria were multiple pregnancy, fetal malformation and second trimester bleeding.

\section{The following outcome measures were selected}

- Pregnancy complications: antepartum hemorrhage including placenta praevia, placental abruption, preeclampsia (blood pressure $=140 / 90$ with proteinuria), eclampsia, preterm prelabour rupture of membranes (rupture of membranes at $<37$ weeks of gestation) and preterm delivery (delivery before 37 completed weeks but after 28 weeks).

- Delivery complications: instrumental delivery by forceps or vacuum extraction, cesarean delivery (elective or emergency), retained placenta and postpartum hemorrhage.

- Neonatal complications and parameters: stillbirth (antepartum or intrapartum death), intrauterine growth restriction, early neonatal death (death within the first 7 days of life), low birth weight (birth weight less than 2,500 g), an Apgar score less than 7 at 5 minutes and admission to the neonatal unit.

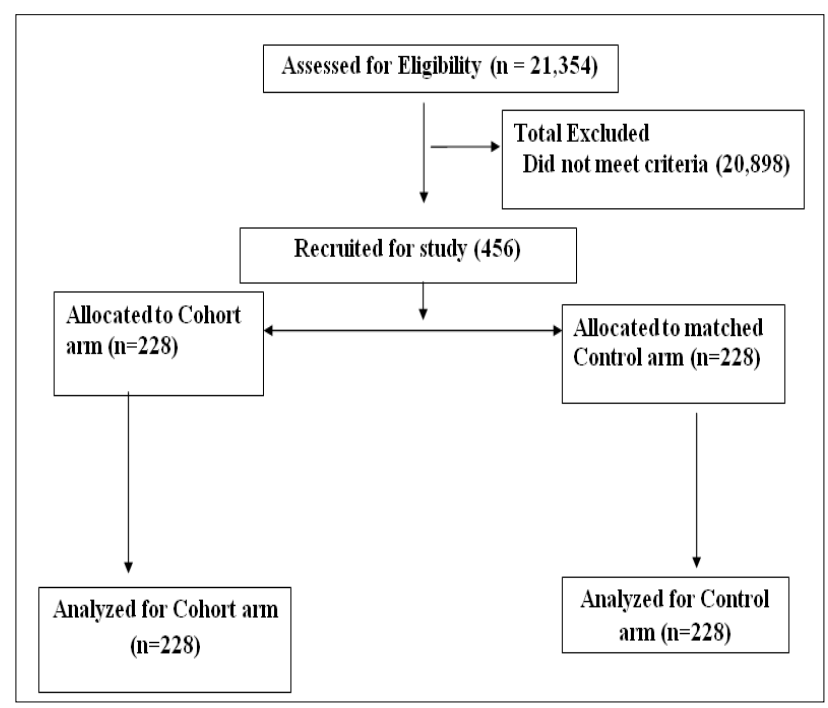

Figure 1: The flow of participants through the study.

Data collection was done by retrieving the hospital number of women that had threatened miscarriage and the controls during the study period from the admission register in the Accident and Emergency department and Gynaecological ward. Then, the case notes were retrieved from the Medical Records Department of the hospital using the hospital numbers. Proformas containing information on the outcome measures were used to extract information from the case notes.

The statistical analysis was done using Epi info version 7.1.5, March 2015 (CDC, Atlanta, Georgia, USA). Numerical variables were presented as mean \pm standard deviation (SD), while categorical variables were presented as number and percentage. Chi square $\left(\chi^{2}\right)$ was used for comparison between groups for categorical data while Student t-test was used for comparison between groups for continuous data. Univariate and multivariate logistic regression analyses were performed where appropriate, and the results expressed as odds ratios (OR) with $95 \%$ confidence intervals $(\mathrm{CI})$. $\mathrm{P}$ value $<0.05$ was considered significant. The approval for the study was sought for and obtained from the Research and Ethical Committee of the Alex Ekwueme Federal University Teaching Hospital, Abakaliki. 


\section{RESULTS}

A total of 21,354 women who delivered after 28 weeks of gestation between 2012 and 2018, were identified from the Department of Medical Records. Of these, 228 (1.1\%) women experienced vaginal bleeding before 12 weeks of gestation, and these women made up of the study cohort, while $21,126(98.9 \%)$ women who had no vaginal bleeding in the first trimester formed the control group from which 228 matched control was drawn from.

The two studied groups were matched with no significant difference between women with and those without first trimester threatened miscarriage with regards to mean age, body mass index (BMI), marital status and parity (Table 1).

Table 1: Comparison of maternal characteristics between women with and those without threatened miscarriage.

\begin{tabular}{|llll|}
\hline Characteristics & $\begin{array}{l}\text { Study } \\
\text { group } \\
(\mathrm{N}=228)\end{array}$ & $\begin{array}{l}\text { Control } \\
\text { group } \\
(\mathrm{N}=228)\end{array}$ & $\begin{array}{l}\text { P- } \\
\text { value }\end{array}$ \\
\hline Mean age (years) & $24 \pm 2.3$ & $24 \pm 2.1$ & 1.00 \\
\hline Mean BMI & $18 \pm 1.4$ & $18 \pm 1.6$ & 1.00 \\
\hline Married n (\%) & $221(96.9)$ & $226(99.1)$ & 0.54 \\
\hline Mean parity & $2.0 \pm 1.4$ & $2.1 \pm 1.6$ & 0.48 \\
\hline
\end{tabular}

Table 2: Comparison of maternal outcome in women with first trimester bleeding and control group $(\mathrm{N}=228)$.

\begin{tabular}{|lllll|}
\hline Outcome & Threatened miscarriage $(\%)$ & Control $(\%)$ & OR (95\% CI) & P-value \\
\hline Preterm delivery & $56(24.6)$ & $10(4.4)$ & $7.1(3.51-14.32)$ & $<0.0001$ \\
\hline PPROM & $47(20.6)$ & $51(22.4)$ & $0.9(0.58-1.41)$ & 0.73 \\
\hline Preeclampsia/eclampsia & $34(14.9)$ & $28(12.3)$ & $1.3(0.73-2.14)$ & 0.49 \\
\hline Placental abruption & $20(8.8)$ & $6(2.6)$ & $3.6(1.40-9.03)$ & 0.01 \\
\hline Placenta praevia & $23(10.1)$ & $10(4.4)$ & $2.4(1.13-5.26)$ & 0.03 \\
\hline Retained placenta & $19(8.3)$ & $7(3.1)$ & $2.9(1.18-6.97)$ & 0.02 \\
\hline Caesarean delivery & $44(19.3)$ & $39(17.1)$ & $1.2(0.72-1.87)$ & 0.62 \\
\hline Instrumental delivery & $12(5.3)$ & $8(3.5)$ & $1.5(0.61-3.81)$ & 0.49 \\
\hline Postpartum haemorrhage & $25(10.9)$ & $11(4.8)$ & $2.4(1.17-5.06)$ & 0.02 \\
\hline
\end{tabular}

PPROM $=$ Preterm prelabour rupture of membranes

Table 3: Comparison of perinatal outcome in women with first trimester bleeding and control group (N=228).

\begin{tabular}{|lllll|}
\hline Outcome & Threatened miscarriage (\%) & Control (\%) & OR (95\% CI) & P-value \\
\hline IUGR & $37(16.2)$ & $12(5.3)$ & $3.5(1.77-6.88)$ & $<0.0001$ \\
\hline Stillbirth & $8(3.5)$ & $6(2.6)$ & $1.3(0.46-3.94)$ & 0.79 \\
\hline Birth weight $<2.5 \mathrm{~kg}$ & $21(9.2)$ & $7(3.1)$ & $3.2(1.33-7.69)$ & 0.01 \\
\hline Apgar at 5 min $<7$ & $34(14.9)$ & $31(13.6)$ & $1.1(0.66-1.88)$ & 0.79 \\
\hline Admission into NICU & $19(8.3)$ & $15(6.6)$ & $1.3(0.64-2.61)$ & 0.59 \\
\hline Early neonatal death & $6(2.6)$ & $9(3.9)$ & $0.7(0.23-1.88)$ & 0.60 \\
\hline
\end{tabular}

IUGR = Intrauterine growth restriction, NICU = Neonatal Intensive Care Unit

The obstetric outcomes for women with and those without threatened miscarriage are shown in Table 2. Women with threatened miscarriage were more likely to have preterm delivery $(\mathrm{OR}=7.1,95 \% \mathrm{CI}=3.51-14.32$, $\mathrm{P}<0.0001)$, placenta praevia $(\mathrm{OR}=2.4,95 \%$ $\mathrm{CI}=1.13-5.26, \mathrm{P}=0.03)$, placental abruption $(\mathrm{OR}=3.6$, $95 \% \mathrm{CI}=1.40-9.03, \mathrm{P}=0.01)$ and retained placenta $(\mathrm{OR}=2.9,95 \% \mathrm{CI}=1.18-6.97, \mathrm{P}=0.02)$. There was also a significant difference in the incidence of postpartum hemorrhage between the two groups and women with first trimester threatened miscarriage were more likely to develop postpartum haemorrhage $(\mathrm{OR}=2.4,95 \% \mathrm{CI}=1.17-5.06, \mathrm{P}=0.02)$. There were no differences in the incidence of preeclampsia/eclampsia, preterm prelabour rupture of membranes, instrumental delivery, or caesarean delivery between the 2 groups of women. Perinatal outcomes for women with and those without threatened miscarriage are presented in Table 3. There was no significant differences in the stillbirth rate, Apgar scores at 5 minutes less than 7 , admission into neonatal intensive care unit and early neonatal death. Threatened miscarriage was associated with intrauterine growth restriction $(\mathrm{OR}=3.5,95 \% \mathrm{CI}=$ $1.77-6.88, \mathrm{P}<0.0001)$ and low birth weight $<2.5 \mathrm{~kg}(\mathrm{OR}$ $=3.2,95 \% \mathrm{CI}=1.33-7.69, \mathrm{P}=0.01)$.

\section{DISCUSSION}

The results of the study indicate that women who have bleeding in the first trimester are at increased risk of later pregnancy complications. This is the largest epidemiological study of obstetric outcome in women 
with threatened miscarriage in Abakaliki. In the study, it was identified that 16 different maternal and perinatal outcomes and have found several associations between early pregnancy bleeding and the poor pregnancy outcomes.

The results of the study clearly showed that preterm delivery, placental abruption, placenta praevia, retained placenta and postpartum haemorrhage are maternal adverse outcomes significantly associated with the pregnant women with threatened miscarriage. The association between threatened miscarriage and preterm delivery ( $<37$ weeks) in this study is in keeping with evidence from previous studies. Batzofin et al and Williams et al reported that threatened miscarriage doubled the risk of delivery before 37 weeks. ${ }^{12,13}$ Strobino and Pantel-Silverman did not find an association between preterm deliveries and light vaginal bleeding in the first or second trimester, whereas Weiss et al found that the risk of delivery before 37 weeks was significantly increased in women irrespective of whether they had light or heavy first-trimester bleeding. ${ }^{14,15}$ It could be speculated that the presence of blood after threatened miscarriage, with the disruption of the chorioamniotic space and the resultant chronic inflammatory reaction, might precipitate preterm labor. A hematoma could also form a nidus for intrauterine infection, which, in turn, could stimulate uterine contractions. The study showed an increased prevalence of placenta previa in the study population when compared with control group. This finding was similar to the findings of studies done in USA, Sri Lanka and London. ${ }^{16-18}$

The location of the chorion frondosum within the uterine cavity in early pregnancy may explain this association, with an inferior position more likely to cause firsttrimester bleeding, as well as a higher risk of placenta previa later on in pregnancy. ${ }^{12}$ Similarly the incidence of retained placenta was higher in women with threatened miscarriage compared with the control. This findings were reported in previous studies. ${ }^{17,18}$ An adhesive scarring between the uterine wall and the placenta at the site of bleeding might be responsible for the increased incidence of retention of placentae in women with threatened miscarriage. ${ }^{12}$

Poor perinatal outcomes encountered in this study were intrauterine growth restriction and low birth weight $<2.5 \mathrm{~kg}$. Low birth weight was associated with firsttrimester bleeding after adjusting for preterm delivery. It has been suggested that growth restriction may be due to some degree of placental insufficiency secondary to scarring at the site of placental bleeding. Study did not find an association between first trimester bleeding, and other poor perinatal outcomes such as stillbirth Apgar at 5 min $<7$, admission into neonatal unit and early neonatal death.

Although it is reassuring that the majority of women with first-trimester bleeding have pregnancy outcomes comparable to those without such bleeding, it is evident that they face a higher relative risk of some adverse obstetric and neonatal outcomes. This information is helpful in terms of counseling women and alerting clinicians to early signs of these complications.

The study has several limitations. First, the patients were drawn from a single centre. A multicentre study is recommended to improve the external validity of the study. Secondly, the retrospective nature of the study limits its validity.

\section{CONCLUSION}

Threatened miscarriage carries a significant risk of adverse maternal and perinatal outcomes compared to the pregnancies not complicated by threatened miscarriage. Knowledge of this increased risk may also facilitate decision making regarding management, for example, timely administration of antibiotics and corticosteroids or decisions regarding mode, place, and timing of delivery, which will inevitably improve neonatal outcome.

\section{ACKNOWLEDGMENTS}

Authors would like to thank the staffs of Department of Medical Records for their support during study.

\section{Funding: No funding sources}

Conflict of interest: None declared

Ethical approval: The study was approved by the Institutional Ethics Committee

\section{REFERENCES}

1. Lykke AJ, Dideriksen KL, Lidegaard O, LanghoffRoos J. First-Trimester Vaginal Bleeding and Complications Later in Pregnancy. Obstet Gynecol. 2010;115:935-44.

2. Obed JY, Adewole IF. Antepartum haemorrhage: the influence of first trimester uterine bleeding. West Afr J Med. 1997; 16:24-6.

3. Konje JC, Ewings PD, Adewunmi OA, Adelusi B, Ladipo OA. The outcome of pregnancies complicated by threatened abortion. J Obstet Gynaecol. 1992;12:150-5.

4. Tongsong $\mathrm{T}$, Srisomboon J, Wanapirak C, Sirichotiyakul S, Pongsatha S, Polsrisuthikul T. Pregnancy outcome of threatened abortion with demonstrable fetal cardiac activity: a cohort study. J Obstet Gynaecol. 1995;21:331-5.

5. Oppenraaij RHF, Jauniaux E, Christiansen OB, Horcajadas JA, Farquharson RG, Exalto N. Predicting adverse obstetric outcome after early pregnancy events and complications: a review. Human Reprod Update. 2009;1:1-13.

6. Wijesiriwardana A, Bhattacharya S, Ashalatha S, Norman S, Siladitya B. Obstetric outcome in women with threatened miscarriage in the first trimester. Obstet Gynecol. 2006;107:557-62. 
7. Saraswat L, Bhattacharya S, Maheshwari A, Bhattacharyad S. Maternal and perinatal outcome in women with threatened miscarriage in the first trimester : a systematic review. BJOG. 2010;117:245-57.

8. Ananth CV, Savitz DA. Vaginal bleeding and adverse reproductive outcomes: a meta-analysis. Paediatr Perinat Epidemiol. 1994;8:62-78.

9. Hertz JB, Heisterberg L. The outcome of pregnancy after threatened abortion. Acta Obstet Gynecol Scand. 1985;64:151-6.

10. Samarakkodya SN, Gunawardena K. A prospective cohort study to assess the association between early pregnancy bleeding and risk of poor pregnancy outcome. Sri Lanka J Obstet Gynaecol. 2019;41:814.

11. Batzofin JH, Fielding WL, Friedman EA. Effect of vaginal bleeding in early pregnancy on outcome. Obstet Gynecol. 1984;63:515-8.

12. Johns J, Jauniaux E. Threatened miscarriage as a predictor of obstetric outcome. Obstet Gynecol. 2006;107:845-50.

13. Williams MA, Mittendorf R, Lieberman E, Monson RR. Adverse infant outcomes associated with firsttrimester vaginal bleeding. Obstet Gynecol. 1991;78:14-8.

14. Strobino B, Pantel SJ. Gestational vaginal bleeding and pregnancy outcome. Am J Epidemiol. 1989;129:806-15.
15. Weiss JL, Malone FD, Vidaver J, Ball RH, Nyberg DA, Comstock $\mathrm{CH}$, et al. Threatened abortion: a risk factor for poor pregnancy outcome, a populationbased screening study. Am J Obstet Gynecol. 2004;190:745-50.

16. Mulik V, Bethel J, Bhal K. A retrospective population-based study of primigravid women on the potential effect of threatened miscarriage on obstetric outcome. J Obstet Gynaecol. 2004;24:249-53.

17. Rajeshwari R, Sreelatha S, Kumar S, Malpure P, Sana S, Shruthi K. A study to evaluate maternal and foetal outcome in pregnant women with first trimester vaginal bleeding. Int $\mathbf{J}$ Gynaecol Obstet Research. 2019;2:40-8.

18. Bhattacharya S, Townend J, Shetty A, Campbell D, Bhattacharya S. Does miscarriage in an initial pregnancy lead to adverse obstetric and perinatal outcomes in the next continuing pregnancy? BJOG. 2008;115:1623-9.

Cite this article as: Nwafor JI, Onuchukwu VJU, Obi VO, Ugoji D-PC, Onwe BI, Ibo CC, et al. A comparative study of pregnancy outcomes among women with and without threatened miscarriage in the first trimester in Abakaliki Southeast Nigeria. Int J Reprod Contracept Obstet Gynecol 2019;8:363943. 